\title{
SPRICHWORT UND WORTSPIEL
}

0 .

Als eine idiomatische Bildung mit dem Satz-Status wird das Sprichwort meist aus der lexikographischen Diskussion ausgeschlossen, weil es Satz ist, auf der anderen Seite wird es im Rahmen der Syntax nicht behandelt, weil es ldiom ist, und so hat das Überprüfen und Testen seiner grammatischen Strukturiertheit wenig Sinn.

Die Spezifik des Sprichwort-Satzes liegt in der linear-horizontalen Kombinatorik seiner Konstituenten. Die Reihenfolge der Sprichwort-Konstituenten ist streng festgelegt.

Wird die Reihenfolge der Sprichwort-Konstituenten aber geändert, wird ein Element ausgelassen oder ersetzt, wird z.B. nur ein Buchstabe oder eine Silbe ausgetauscht, wird das Sprichwort verkürzt oder durch neue Element erweitert, kann der Sprichwortsatz einen ganz anderen Sinn bekommen, er kann auf diese Weise ja zur Negation von sich selbst - zum Antisprichwort ${ }^{1}$-werden. Zum Beispiel:

Liebe geht durch den Wagen ("Antisprichwörter", III, S. XII; nach der Quelle: Liebe geht durch den Magen.)

Alte Liebe kostet nichts ("Antisprichwörter", I, S. 95; Quelle: Alte Liebe rostet nicht.)

Aller Umfang ist schwer ("Antisprichwörter", I, S. 3; Quelle: Aller Anfang ist schwer.)

Bildung schützt vor Torheit nicht ("Antisprichwörter", III, S. XV; Quelle: Alter schützt vor Torheit nicht.)

Wissen ist Macht, nichts wissen macht nichts! ("Antisprichwörter", III, S. X; Quelle: Wissen ist Macht.)

1.

Im modernen Sprachgebrauch sind Tendenzen eines freieren, spielerischen Umgangs mit dem Sprichwort zu beobachten. Das trifft ganz besonders auf die Sprache der Presse zu. Parömiologische Untersuchungen verschiedener Zeitungen in den letzten sechs Jahren $^{2}$ zeigen, daß bei der Umformulierung von Sprichwörtern ganz reguläre

1 Unter "Antisprichwort" wird hier im Sinne von Wolfgang Mieder die wortspielerische Umformulierung des ursprünglichen Sprichworttextes verstanden, womit die altüberlieferte Sprichwortweisheit lächerlich gemacht, ja sogar völlig negiert wird. 
Verfahren - sowohl auf der lexikalischen, als auch auf der morphosyntaktischen Ebene - festzustellen sind. Alle bis jetzt registrierten Umänderungen von Sprichwörtern können in neun Klassen (oder Typen) eingeordnet werden ${ }^{3}$.

\section{TYP}

Die originale Form des Sprichworts wird beibehalten, z.B. Macht geht über Recht. (Simrock)

\section{TYP}

Man übernimmt das syntaktische Modell vom ursprünglichen Sprichwort, aber die Lexik ist vollkommen geändert. Z.B. Spiel - Satz - Griff ans Herz ("Sport-Bild", 1989), nach der Quelle: Veni, vidi, vici.

\section{TYP}

Man übernimmt das syntaktische Modell vom ursprünglichen Sprichwort, und die Lexik ist nur teilweise geändert; nur ein Bestandteil (eine Konstituente) des Sprichworts wird durch ein außerhalb des Sprichworts genommenes Element ersetzt. Z.B. Lügen haben schöne Beine (Mieder/Röhrich, 1977), nach der Quelle: Lügen haben kurze Beine.

IV TYP

Partielle oder völlige Umstellung (Permutation, Metathese) der innerhalb des Sprichworts vorhandenen Bestandteile. Z.B. Über die Sterne zu den Dornen... (Originalversion im Kroatischen: Preko zvijezda do trnja... aus "Slobodna Dalmacija", 1992), nach der Quelle: Per aspera ad astra./Preko trnja do zvijezda.

2 Vgl. Matulina Željka (1991): Upotreba poslovica u sportskim novinama s hrvatskog ili srpskog $i$ njemackog govornog područja, in: Zbornik radova "Kontrastivna jezička istraživanja", Novi Sad, S. 216-224; Matulina Željka (1991): Sprichwörter in Artikelüberschriften der "Slobodna Dalmacija" und einiger vergleichbarer österreichischer Tageszeitungen, in: Znanstvena revija, 1, Maribor, S. 97-108; Matulina Željka (1991): Upotreba poslovica u dnevnim novinama, in: (Hrsg. Branko Tošović) "Jezik i stil sredstava informisanja", Sarajevo, S. 48-66; Matulina Željka (1992): Der Gebrauch von Sprichwörtern in der Zadarer Wochenzeitung "Narodni list", in: Proverbium 9, Vermont, USA, S. 139-158; Matulina Željka (1992): Upotreba poslovica u naslovima austrijskog tjednika "Wochenpresse", in: Radovi Filozofskog fakulteta u Zadru, sv. 30, Zadar, S. 69-91; Matulina Željka (1993): Upotreba poslovica u osječkom dnevnom listu "Glas Slavonije", in: Radovi Filozofskog fakulteta u Zadru, sv. 31, Zadar, S. 155-176.

3 Es muß hier aber auf die Tatsache aufmerksam gemacht werden, daß ein umformuliertes Sprichwort sehr oft zweien oder sogar mehreren Strukturtypen gleichzeitig zugerechnet wird. Aus den bisher gemachten Analysen geht hervor, daß bei der Sprichwortvariierung meistens der dritte und der neunte Typ zusammenwirken. Hier ein Beispiel: Schweigen war Gold: Warum die Journalisten zur real existierenden DDR nichts zu sagen hatten. ("Spiegel", 1990; zu der Quelle: Reden ist Silber, Schweigen ist Gold. An diesem Beispiel können wir das Zusammenwirken dreier Strukturtypen beobachten: Eliminierung einer Sprichwortkonstituente nach dem VIII Typ (Schweigen ist Gold), Ersatz eines Sprichwortelements nach dem III Typ (Schweigen war Gold statt Schweigen ist Gold) und zuletzt Erweiterung des Sprichworts durch einen postpositionierten Satz nach dem IX Typ (Warum die Journalisten zur real existierenden DDR nichts zu sagen hatten?) 


\section{TYP}

Das syntaktische Modell ist geändert, aber die Lexik ist völlig erhalten. Z.B. Entscheiden Sie sich deshalb für das 5er - Combi. Dann haben Sie den Spatz in der Hand - und die Taube auf dem Dach kann Ihnen trotzdem nach als Volltreffer ins Haus flattern! (Aus einem Werbetext), nach der Quelle: Besser der Spatz in der Hand als die Taube auf dem Dach.

\section{VIT TYP}

Das syntaktische Modell und die Lexik sind beide geändert; wenigstens ein Element entweder vom syntaktischen Modell des ursprünglichen Sprichworts oder von seiner Lexik muß erhalten bleiben, um das ursprüngliche Sprichwort zu assoziieren, z.B. Hören und fühlen ("Kurier", 1989), nach der Quelle: Wer nicht hören will, muß fühlen. VIII TYP

Kombination zweier Sprichwörter oder eines Sprichworts und einer anderen verwandten Art (z.B. einer Redewendung), z.B. Geld oder Glück ("Wochenpresse", 1989), nach den Quellen: (a) Geld oder Leben und (b) Geld allein macht nicht glücklich.

VIII TYP

Ein Teil des ursprünglichen Sprichworts wird eliminiert: Wer A sagt... ("Wochenpresse", 1990), nach der Quelle: Wer A sagt, muß auch B sagen.

\section{TYP}

Verschiedene Erweiterungen des Sprichworts werden vorgenommen, z.B. Einfügung eines neuen Elements oder komplexerer Einheiten vor oder nach dem Sprichwort (präoder postpositionierte Erweiterungen). Vor allem sind die sog. "Wellerismen"4 interessant. Hier einige Beispiele: Zeit ist Geld, sagte der Ober und addierte das Datum mit (Bayer), nach der Quelle: Zeit ist Geld. Eine Hand wäscht die andere manchmal tut es auch ein Finger (Finger = Familienname; "Wochenpresse", 1987), nach der Quelle: Eine Hand wäscht die andere.

\section{2.}

In diesem Beitrag möchte ich nur exemplifikativ und ohne Anspruch auf Vollständigkeit zeigen, mit welchen morphosyntaktischen Mitteln das Sprichwort variiert wird.

Aufgrund einer Belegsammlung von 290 Texten mit deutschen und kroatischen Sprichwörtern werde ich nur den V und den VI Typ der Umformulierung präsentieren. Im ersten Fall ist das syntaktische Modell des Sprichworts geändert, aber die Lexik ist völlig erhalten. Im zweiten Fall sind das syntaktische Modell und die Lexik beide

Nach der Dickenschen Figur des Samuel Weller genannt; hier wird ein Sprichwort von jemandem gesagt und gleichzeitig durch einen anderen Ausdruck vervollständigt, der "zur früheren Äußerung wie die Faust aufs Auge paßt", z.B. Was sich liebt, das neckt sich, sagte die Katze zur Maus und fraß sie; Angaben nach Bayer, a.a.O., S. 14; oder: Alles hat ein Ende. Nur die Wurst hat zwei. 
geändert, und vom ursprünglichen Sprichwort ist nur ein Element erhalten, um das Sprichwort zu assoziieren.

Die Belege (es handelt sich um 150 deutsche und 140 kroatische Texte) sind folgenden Zeitungen entnommen:

Spiegel (Jahrgang 1990)

Westdeutsche Allgemeine Zeitung (Jahrgang 1991)

Fußball-magazin (Jahrgang 1989)

Zeit (Jahrgang 1990)

Slobodna Dalmacija (Jahrgang 1989)

Sportske novosti (Jahrgang 1989)

Glas Slavonije (Jahrgang 1989)

Tjednik odabranih priloga (Jahrgang 1990)

Dazu kommen noch 32 Belege aus der Sprichwortsammlung Antisprichwörter von W. Mieder (Erscheinungsjahre 1982-1989).

3.

Die morphosyntaktischen Änderungen, die sich auf Grund der Analyse der oben aufgeführten Zeitungen herausgestellt haben, können folgendermaßen gruppiert werden:

(1) Ummodellierung der Satzkomposition (Tabelle 2)

(2) Ummodellierung der Satzstruktur in bezug auf die Zahl der Konstituenten (Tabelle 3)

(3) Änderung der Satzart (Tabelle 4)

(4) Änderung der Wortart der Konstituenten (Tabelle 5)

(5) Änderung des Wortbildungsmusters der Konstituenten (Tabelle 6)

(6) Änderung der morphologischen Kategorien der Konstituenten (Tabelle 7 für das Verb und Tabelle 8 für das Substantiv)

(7) Sonstige Änderungen, z.B. Wort- und Satznegation (Tabelle 9)

Nach den statistischen Angaben ${ }^{5}$ (sie sind den Tabellen zu entnehmen) scheinen die Umformulierungen auf der SATZEBENE am beliebtesten zu sein, und zwar trifft das mehr auf das Kroatische als auf das Deutsche zu. So wird z.B. in 7 von 8 Fällen die Quelle durch ein präpositioniertes Syntagma erweitert. Z.B. Denken wir an das alte Sprichwort: Müßiggang ist aller Laster Anfang. ("WAZ", 1991;

Quelle: Müßiggang ist aller Laster Anfang)

5 In den tabellarischen Übersichten werden folgende Abkürzungen verwendet: ANTI (= Sammlung Antisprichwürter) FUSSB (= Fußball-magazin), WAZ (= Westdeutsche Allgemeine Zeitung), $S D$ (= Slobodna Dalmacija), $S N$ (= Sportske novosti), GS (= Glas Slavonije), TOP (= Tjednik odabranih priloga). Die Zahl neben der Abkürzung bedeutet die Stelle des Beleges im Sprichwortverzeichnis am Ende dieses Beitrags. 
In 4 von 6 Fällen wird aus einem einfachen Satz ein zusammengesetzter Satz gebildet. Z.B. Geld allein macht nicht glücklich - aber es beruhigt. ("WAZ", 1991; Quelle: Geld allein macht nicht glücklich.)

Während postpositionierte Sprichworterweiterungen im Deutschen und im Kroatischen gleich vertreten sind, sind die internen Sprichworterweiterungen wieder im Kroatischen häufiger als im Deutschen. Ein Beispiel: "Posijano" je ono što neprestano, pa i sada u dramatičnim razmjerima - "žanjemo". (Die buchstäbliche Übersetzung lautet etwa: "Gesät" ist das, was wir ständig, auch jetzt unter diesen dramatischen Umständen "ernten"; "Slobodna Dalmacija, 1988; Quelle: Kakva sjetva, takva žetva. / Wie die Saat, so die Ernte.)

Im Bereich der Satzstruktur, in erster Linie betrifft das die Zahl der Konstituenten, scheint wieder das Kroatische mehr von den Veränderungen in diesem Bereich Gebrauch zu machen. Am häufigsten wird eine Konstituente aus dem Satz eliminiert. Ein Beispiel: Früh übt sich... ("WAZ", 1991; Quelle: Früh übt sich, wer ein Meister werden will.)

Auch die Satzart wird im Sprichwort gerne geändert. Zum Beispiel wird aus einem Aussagesatz ein Fragesatz, oder aus einem Imperativsatz ein Aussagesatz. Die Zahl der Belege besagt, daß diese Erscheinung im Deutschen häufiger ist als im Kroatischen. Ein Beispiel: Was tun, wenn Zeit Geld ist? ("Spiegel", 1990; Quelle: Zeit ist Geld.)

Was die morphologischen Kategorien einzelner Konstituenten des Sprichworts anbelangt, hat sich herausgestellt, daß im Kroatischen die Kategorien des Tempus, des Modus, des Genus verbi öfter verändert werden als im Deutschen, während im Deutschen häufiger die Änderungen im Bereich der Person und des Numerus sind. Z.B. Wer sucht, der findet. ("WAZ", 1991; Quelle: Suchet und ihr werdet finden!) oder ...da se i u ovoj oblasti možemo prostirati samo onoliko koliko nam je pokrivač dugačak. ("Slobodna Dalmacija", 1989; Quelle: Prostri/pokrij se onoliko koliko ti doseže pokrivač!)

Satz- und Wortnegation sind im Deutschen mehr vertreten als im Kroatischen. Ein Beispiel: Ende gut, nicht alles gut... ("Fußball-magazin", 1989; Quelle: Ende gut, alles gut.)

4.

Aus dem oben Dargelegten ist zu schließen, daß ebensowohl im Deutschen als auch im Kroatischen neben den lexikalischen Mitteln auch alle zur Verfügung stehenden morphosyntaktischen Sprachmittel gebraucht werden, um aus dem ursprünglichen Sprichwort eine umformulierte, humorvoll-ironische, Variation zu machen. Die durchgeführte Analyse an einem begrenzten Korpusmaterial hat gezeigt, wie die einzelnen morphosyntaktischen Mittel eingesetzt werden und wie oft. Auf diese Weise können Gemeinsamkeiten und Unterschiede zwischen den beiden hier zu konfrontierenden Sprachen beobachtet werden. So kann man feststellen, daß das Deutsche am meisten folgende Möglichkeiten nützt: 
(1) Änderung der Wortart einer Konstituente (6mal im Korpus)

(2) Änderung der Satzart (4mal im Korpus)

(3) postpositionierte Sprichworterweiterung (3mal)

(4) Satz- und Wortnegation (2mal)

Am zahlreichsten sind im Kroatischen folgende Änderungen:

(1) präpositionierte Sprichworterweiterungen (7mal)

(2) Ein einfacher Satz wird zu einem zusammengesetzten Satz (5mal)

(3) Reduzierung der Zahl der Konstituenten (8mal)

(4) Änderung der morphologischen Kategorie der Konstituenten (vor allem des Verbs, 11mal)

(5) Änderung der Reihenfolge der Konstituenten (2mal)

Am wenigsten werden im Deutschen die morphologischen Kategorien beim Verb und beim Substantiv geändert, im Kroatischen aber die Wortart und das Wortbildungsmuster der Konstituenten.

\section{LITERATUR}

Beyer, Horst und Annelies (1986): Sprichwörterlexikon, Verlag C.H. Beck, München Mieder, Wolfgang (1973): Verwendungsmöglichkeiten und Funktionswerte des Sprichworts in der Wochenzeitung (Untersuchung der Zeit für das Jahr 1971), in: Muttersprache, LXXXIII, S. 89-119

Mieder, Wolfgang (1979): Sprichwörtliche Schlagzeilen in der Wochenzeitung (Untersuchung der Zeit für das Jahr 1977), in: Muttersprache, XXXVIII, S. 93-105

Mieder, Wolfgang (1982): Antisprichwörter Bd. I; (1985): Antisprichwörter Bd. II; (1989): Antisprichwörter Bd. III, Quelle und Meyer, Heidelberg/Wiesbaden

Röhrich, Lutz/Mieder, Wolfgang (1977): Sprichwort, J.B. Metzlersche Verlagsbuchhandlung, Stuttgart

Simrock, Karl (1988): Die deutschen Sprichwörter, Reclam, Stuttgart

Skarpa, Vicko (1909): Hrvatske narodne poslovice, Šibenik

Povzetek

PREGOVOR IN BESEDNA IGRA

V sodobnih besedilih sredstev javnega obveščanja - govornih in pisnih - je opazna izrazita težnja za preoblikovanje pregovorov, tako $v$ nemškem kot $v$ hrvaškem jeziku. Na osnovi skromnega korpusa 290 časopisnih besedil $v$ hrvaščini in nemščini, v katerih so se pojavljali pregovori, sem želela $v$ tem delu s primeru prikazati, $s$ katerimi morfosintaktičnimi sredstvi so možne variacije izvirnih oblik pregovorov, in kako pogosto se pojavljajo posamezne vrste teh sprememb.

Analiza korpusa je med drugim pokazala, da so v nemščni v rabi v glavnem naslednje jezikovne možnosti: (1) spremembna besedne vrste v konstituentah, (2) sprememba vrste stavka, (3) postpozicionirano dopolnjevanje 
pregovora in (4) negacija stavka oz. besede. $V$ hrvaščini pa so najpogostejša naslednja sredstva: (1) prepozicionirano dopolnjevanje konstituent, (2) spreminjanje prostega stavka v zloženi stavek, (3) zmanjšanje števila konstituent, (4) sprememba morfoloških kategorij konstituent in (5) zamenjava vrstnega reda konstituent. $V$ nemščini se najmanj menjavajo morfološke kategorije konstituent (npr. glagola in samostalnika), $v$ hrvaščini pa vrstni red besed in vzorec za tvorbo besed.

\section{ANHANG}

\section{BELEGSAMMLUNG VON VARIIERTEN SPRICHWÖRTERN}

\section{Der Spiegel}

1 Strich für Strich - ein Staedtler

2 Strich für Strich - ein Wetterfrosch

3 "Zeit ist Geld. Aber nur, wenn man keine Zeit hat." (Frenzel)

4 Strich für Strich - ein Staedtler

5 Strich für Strich - ein Staedtler

6. Guter Hausrat ist teuer. Oder richtig versichert.

7. In vino Veritas?

8. Strich für Strich - ein Staedtler

9. Strich für Strich - ein Trickfilm-Star

10. Mit dem Alter kommt die Ruhe.

11. Einer für alle!

12. Wer Wind sät

13. Strich für Strich - ein Staedtler

14. "Liebe öffnet jeden Tresor"

15. Einer für alle!

16. Ausnahmen sind nicht immer Bestätigung der alten Regel; sie können auch Vorboten einer neuen Regel sein.

17. Zink. Sicher ist sicher.

18. "Größe ist nicht alles." Seneca

19. Erst die Sicherheit, dann der Strom.

20. Haar für Haar

21. Was tun, wenn Zeit Geld ist?

22. Klein - aber oho...!

23. Strich für Strich - ein Staedtler

24. Strich für Strich - ein Staedtler

25. Neues Spiel, neues Glück

26. Strich für Strich - ein Staedtler

27. Bargeld lacht

28. Einer für alle Tage!

29. "Wer leuchten will, muß brennen" 
30. Schweigen war Gold: Warum die Journalisten zur real existierenden DDR nichts zu sagen hatten.

31. Wie das Land, so das Jever.

32. Die schönen Dinge des Lebens brauchen ihre Zeit.

33. Der Praxisletfaden zu "Irren ist menschlich" jetzt neu im Buchhandel...

34. Lügen haben kurze Beine.

35. Giftgas ging, Unrecht bleibt

36. Strich für Strich - ein Wetterfrosch

37. Strich für Strich - ein Staedtler

38. Haar für Haar

39. Nichts ist unmöglich

40. Haar für Haar

41. Rechnung ohne Witwe

42. Alles oder nichts

43. Klein - aber oho...!

44. Eigenes Salz

45. Haar für Haar

\section{Westdeutsche Allgemeine Zeitung}

1. Aber aufgeschoben ist nicht aufgehoben, und der 11.11. kommt da dem ZDF gerade recht - frei nach der Devise: Mir lasse halt nix verkomme...

2. Getreu dem Motto "Angriff ist die beste Verteidigung" kündigte der Staatschef eine Verfassungsreform der V. Französischen Republik an.

3. Aus den Augen, aus dem Sinn.

4. Aus den Augen, aus dem Sinn.

5. Aus den Augen, aus dem Sinn.

6. Aus den Augen, aus dem Sinn.

7. Aus den Augen, aus dem Sinn.

8. Aus den Augen, aus dem Sinn.

9. Geld allein macht nicht glücklich - aber es beruhigt.

10. Möbel sind nicht alles im Leben

11. Möbel sind nicht alles im Leben.

12. Böse Bemerkungen wie "Lieber ein Kind auf dem Kissen als auf dem Gewissen!" gehören ins Kabarett...

13. "Glück und Glas, wie leicht zerbricht das!" reimt der Volksmund.

14. Die "kurz + gut" Anlage

15. Hochmut tut bekanntlich selten gut.

16. Werbung kennt keine Grenzen.

17. Früh übt sich...

18. Früh übt sich...

19. Übung macht den Meister: Die Französin Fabienne Hupin bei der praktischen Ausbildung an Bord. 
20. Andere sind der Meinung, daß Müßiggang aller Laster Anfang sei, oder daß die Ursachen für Drogensucht in der Kindheit zu suchen seien.

21. Denken wir an das alte Sprichwort: Müßiggang ist aller Laster Anfang.

22. Liebe deinen Nächsten wie dich selbst.

23. Da ist guter Rat teuer

24. Erfolgreicher Start in die Rückrunde wäre Gold wert.

25. Wer viel erntet, hat allen Grund, neu zu säen.

26. Eine Papierschwalbe macht noch keinen Sommer

27. Eine Papierschwalbe macht noch keinen Sommer.

28. "Lieber eine Taube im Strafraum als der Ball im Tor" gab sich Schalkes Präsident Günter Eichberg nach dem Schlußpfiff erleichtert...

29. Wer sucht, der findet.

30. Wer sucht, der findet.

31. Wer wagt - gewinnt!

32. Gut gezählt ist halb gewonnen!

33. Zeit ist Geld geworden, kostbares Gut...

\section{Antisprichwörter}

1. "Sicher ist sicher", sagte der General. "Todsicher", sagte der Soldat.

2. Wer schläft, sündigt nicht. Aber wer vorher sündigt, schläft nachher besser!

3. Die Frau ist ein notwendiges Übel: Die Ehefrau ist das Übel, die Geliebte das Notwendige.

4. Ein Irrtum gibt den anderen.

5. Wer nicht will, der wird gewollt.

6. Was du heute kannst besorgen, kannst du dir morgen bestimmt nicht mehr leisten.

7. Der Lohn macht die Musik.

8. "Kein Mensch muß müssen" - Aber es ist doch eine Frage, ob er nicht manchmal wollen muB.

9. Der Mensch ist, was er ißt. Warum ist er nicht, was er ist?

10. Wer einmal lügt, dem glaubt man nicht... Besser: zweimal lügen.

11. Kriege haben kurze Beine, denn, wer einmal kriegt, dem glaubt man nicht...

12. Die Linke weiß, was die Rechte will, die Rechte weiß, was die Linke will. Nur sich selbst zu erkennen ist schwer.

13. Die Liebe macht nicht blind, aber sehr kurzsichtig.

14. Vaterlandsliebe kennt keine (fremden) Grenzen.

15. Liebe geht durch den Briefkasten.

16. Die Liebe kommt mit dem Wagen.

17. Alte Liebe rastet nicht.

18. Alte Liebe kostet nichts.

19. Hunde die beißen, können nicht bellen.

20. Wenn die Menschen sagen, sie hätten ihr Herz verloren, ist es meistens nur der Verstand. 
21. Appetit kommt beim Essen. Hauptsächlich, wenn andere essen.

22. Ein Sprichwort stimmt selten allein.

23. Was lange gärt, wird endlich Mut.

24. Wissen ist Macht. Wenn man das Wissen zum Machtwissen macht.

25. Er heulte mit den Wölfen, doch sie verstanden ihn nicht und fraßen ihn auf.

26. Beine machen Leute.

27. Kommt Zeit, kommen Raten.

28. Man soll das Gehalt nicht vor der Steuer loben!

29. Alles hat ein Ende, nur "Dallas" wird fortgesetzt.

30. Wer den Pfennig nicht ehrt ist die Valuta nicht wert.

31. Wo kein Wille ist, sollte wenigstens ein Ausweg sein.

32. Wo ein Wille ist, ist auch ein Weg. Irren ist, menschlich.

Fußball-magazin

1. Lieber Sieger als Flieger

2. Man soll den Tag nie vor dem Abend verdammen

3. Viel gewonnen, alles verloren

4. Einer wie keiner

5. "Auf Regen folgt Sonne" scheint Edelgard ihren Uwe liebevoll zu trösten

6. Einmal verloren ist keinmal

7. Jetzt macht der Thon die Musik

8. Tore heilen alle Wunden

9. Von "Morgenstund hat Gold im Mund" wollen wir gar nicht erst reden.

10. Diese drei Monate haben Wunden geschlagen, so tief, daß sie auch ein gutes Ende nicht so schnell vernarben läßt.

11. Nehmen wir nur mal, Ende gut, alles gut!

12. Aber, wie sagt ein altes Sprichwort: "Was nicht ist, kann ja noch werden."

13. Wer zuletzt lacht, lacht am besten

14. Ein Tiefschlag, der erst verdaut werden mußte und: Wer den Schaden hatte, brauchte sich auch um den Spott nicht sorgen.

15. "Aus Fehlern lernt, man, jetzt habe ich den Kredit wieder zurückgeholt", erklärt Müller seine Wandlung.

16. Ende gut, nicht alles gut...

17. Wer einmal trifft, verlernt es nicht

18. Alles ist machbar, wenn man es will

19. Geld stinkt nicht

20. Nach Regen scheint Sonne

21. Wo ein Wille ist, ist auch ein Weg

22. Gutes muß nicht immer teuer sein

23. Wo der Wille ist, findet sich auch der Weg

24. Übung macht den Meister

25. "Der Erfolg gibt es nicht ohne Schweiß" 
26. Für Siege ist man nie zu alt

27. Lernen und lehren

28. Team für Team, Mann für Mann

Zeit

1. Guter Rat fällt nicht vom Himmel

2. Jede D-Mark hat drei Seiten

3. Die Hypo. Eine Bank - ein Wort.

4. Weniger ist mehr.

5. Weniger ist mehr.

6. Weniger ist mehr.

7. Jede D-Mark hat drei Seiten.

8. Ein Vermögen macht man nicht mit Glück, sondern mit Verstand.

9. Neuer Besen, altes Reisig

10. Korsika: Ruhe nach dem Sturm

11. Der Schein trügt

12. Aus dem Leiden lernen

\section{Slobodna Dalmacija}

1. Čeka treće i više sreće

2. Evica ... još uvijek pamti i glasno se poziva na opće poznatu poslovicu da "bez treće nema sreće"...

3. Kad hoćemo...

4. Nema što, kad hoćemo, nitko nam ravan nije!

5. Plati, pa veslaj!

6. Sve ili ništa

7. Ako su mislili biti prvi, morali su ići na sve ili ništa.

8. Kome 13. pa sreća?

9. Bronca dvojac krasi!

10. Ispeci pa reci

11. Finiš Maksimir krasi

12. I jedan vrijedan

13. Prekinuo, priznao, poništio

14. Preko Gripa do polufinala

15. Ispeci pa reci

16. Bronca dvojac krasi!

17. Vrijeme je sudac

18. Kroz trnje do zvijezda ili...

19. Poletarci visoko lete

20. Vidjela, dopalo mi se, probala...

21. "Velebit" i "Omladinac" kolo vode... 
22. Ali, što sve to skupa vrijedi kada ne učimo ništa od povijesti koja je (kažu) učiteljica života.

23. "U ljubavi i ratu sve je dopušteno" kaže engleska poslovica, a sport je i ljubav ... i rat ...

24. Tada je posijano ono što neprestano - žanjemo

25. "Posijano" je ono što neprestano, pa i sada u dramatičnim razmjerima - "žanjemo".

26. A lancun prekratak.

27. Umjesto toga, na javnoj su sceni i drugačija reagiranja, pa i takva po kojima je taj pokrivač trebalo pošto-poto, makar umjetno, rastegnuti.

28. ...iz kojega treba izvući pouku da se i u ovoj oblasti možemo prostirati samo onoliko koliko nam je pokrivač dugačak.

29. Iznimke samo potvrdjuju pravilo.

30. Javni transferi bez ograničenja svode se na devizu "plati koliko možeš", makar i nemao.

31. ...čime bi se našla u financijskom vakuumu, nakon čega bi nam i vrhunski sport došao na trulu granu. A s trule grane ne leti se u visine.

32. Riječi jedno - papiri drugo

33. Djevojke kolo vode

34. Evropljani kolo vode

35. Ima jedna izreka: "Poslušaj savjet onoga tko te voli"...

36. Opeklo nas je mlijeko, pa sada pušemo i na jogurt, kaže neka poslovica.

37. Zato, Vidjak, nikad ne reci "hop"...

38. Nema što, kad hoćemo, nitko nam ravan nije!

39. Zna se, jedna nesreća nikad ne dolazi sama.

40. Napad najbolja obrana

41. To je (kaže Curkovic) ostalo iz vremena kad u nas "lijeva nije znala što radi desna".

42. Naime, sada možemo pripremati ražanj, jer zec više nije u šumi.

43. Srećom, mač ima dvije oštrice!

44. Ne kaže se bez veze: "I kada su siti vuci, a ovce na broju javlja se problem: kako nahraniti ovce?"

45. Stručnjaci su se potajno bojali da "Dinamo", goneći lisicu, ne istjera vuka.

46. Zašto šutnja nije zlato?

47. Novac je baš - sve

48. Treća strana medalje

49. Gorko, ali šećer na kraju.

50. U Nikoliću je spas

51. Šeser na kraju?

52. Svi u kupe - Šimun u špade

53. Bod po bod za titulu

54. Baldekinu treća sreća

55. Peta, pa sreća 
56. Nije vrag tako crven.

57. Doduše, u maratonu od 34 kola u kojem malo tko zna tko će popiti, a tko platiti, možda se na kraju ti utjecaji ... izmijene.

58. Lijeva i desna ruka

59. Ruka ruku mije

60. S riječi na-barut!

Sportske novosti

1. Vuk u janjećoj koži

2. Dobro je da postoje turističke agencije koje iznajmljuju autobuse, a navijači se drže one "tudje nećemo, svoje ne damo".

3. Sva sreća da se navijači nisu držali one "kad nešto činiš, čini to do kraja".

4. ,... koji ističu pretpostavku da sve to miriše na onu narodnu "Kadija te tuži - kadija ti sudi".

5. I to ce vrijeme pokazati.

6. A u nas liječnici nogometaški doping zamotaš̀e u celofan. I bit će - pojeo vuk magare. Naša posla!

7. Rekoše ljudi, samo mijena stalna jest!

8. S obzirom da NSJ nema dinara ..., preporučujemo odgovornima u NSJ da isplati osobnih dohodaka svojih trudbenika obave izravno, u devizama, po sistemu "prave ražanja, a zec u šumi".

9. No, Hinault nije "revanšista" koji bi govorio u stilu: Što se babi tilo, to se babi snilo".

10. Koliko ljudi - toliko mišljenja!

11. Tko vrijedi neka i košta...

12. Odmah se mora reći, svaka čast Komisiji, koja je morala ispravljati "krivu Drinu", kad su bili u pitanju ovogodišlji prelasci naših rukometaša i rukometašica.

13. (s. Nr. 12)

14. Vremena se, eto mijenjaju, a kolo sreće neprestano se okreće...

15. (s. Nr. 14)

16. (s. Nr. 14)

17. (s. Nr. 14)

18. A "Zvezda", naše zlato, uporno igra Šaronju. Mijenja boje, ćud ne. Farba sve po spisku.

19. Ako je suditi po onoj, da se dan po jutru poznaje, prvoligašu s Kantride se onda lijepo piše.

20. Prije se znalo - popu pop, a bobu bob.

21. Kaže se: tko pjeva - zlo ne misli, ali nikad se ne zna što navijači misle dok pjevaju.

22. Suci se vani ponašajo po kršćanskim načelima: ja sam gospod bog i nemoj imati drugih bogova osim mene!

23. Uzmimo npr. poštenje, fair play, ili onu ljubi bližnjega svoga. 
24. Zaista, u pjeni nelogičnosti, što ih izazivajo domaći valovi bazena, teško je pucati i plivati, a da "vuk bude sit i sve ovce na broju"...

25. Znamo i to da odijelo ne ćini čovjeka!

26. Ima i ona: po jutru se dan poznaje, a navečer hladi.

27. Pa ona ono: jedno misli, drugo govori a treće radi.

28. Ispod Mire sto vragova vire.

29. ... a druga ... o neodlučnom čovjeku koji je htio dograbiti SVE, pa na kraju nije uhvatio NIŠTA.

30. Samo što se nikad ne zna što narod misli kad (tko) pjeva - upozorio me svemirac.

31. To je u redu, jer tko pjeva zlo ne misli.

32. U Rim stići nije lako, al se može malom žvakom.

33. Kažu da je svaki čovjek svoje sreće kovač.

34. Ona engleska mudrost da je vrijeme novac kod nas ne važi.

35. Kod nas je vrijeme kavana, u repu kot liječnika, stajanje na šalteru, "sto godina te nisam vidio", "idemo na jedno s nogu"!

\section{Glas Slavonije}

1. Kondicija najbolja obrana

2. Cilj ne bira sredstvo

3. Preko prepona do reprezentacije

4. Preko SSSR-a do naslova

5. Preko pionira do naslova?!

6. Dogovor kuću gradi

7. Kriva Drina

8. Sve se može, kad se hoće

9. Jedan, ali vrijedan

10. Jedan, ali vrijedan

11. Nikad nije kasno

12. BSK kolo vodi

13. "Željezničar" kolo vodi

14. "Klinke" kolo vode

15. Svemu dodje kraj

16. Na mladima svijet ostaje

17. Kakav otac - takva hći

18. Ne ponovilo se!

19. Bilo, ne ponovilo se

20. Prvo, pa-derbi

21. S riječi na djelo

22. Ili Mladost ili - "out"!?

23. Ili Mladost ili - "out"

24. Prvo štalica...

25. U zdravu tijelu... 
1. Hvali bližnjega svoga

2. Malo, ali fino

3. Malo, ali obavezno

4. Kratko, ali slatko

5. Novac ne čini sreću

6. Jedan, ali vrijedan

7. Never too late (Nikad prekasno)

8. Paul McCartney: Kod kuće je najljepše.

9. Ljubav se (uvijek) ne može kupiti

10. Ljubav ide kroz kožu

11. Prvi mačići...

12. Kakvo vrijeme, takav smijeh

13. Istaknute oči - one su ogledalo duše

14. Danny Huston - kakavo otac, takav sin

15. Filmska povijest se ponavlja

16. Sad ili nikad

17. Emocionalni tuk na utuk

18. "Gavran" visoko leti

19. Zabranjeno voće narodnjačkih vila

20. Vrijeme je najbolji sudac

Tabelle 1: KORPUS

\begin{tabular}{|c|c|c|c|c|c|}
\hline JAHR & DEUTSCHE ZEITUNG & $\begin{array}{c}\text { ZAHL } \\
\text { DER } \\
\text { BELEGE }\end{array}$ & JAHR & KROATISCHE ZEITUNG & $\begin{array}{c}\text { ZAHL } \\
\text { DER } \\
\text { BELEGE }\end{array}$ \\
\hline 1990 & "Spiegel" & 45 & 1909 & "Slobodna Dalmacija" & 60 \\
\hline 1991 & $\begin{array}{l}\text { "Westdeutsche Allgemeine } \\
\text { Zeitung" }\end{array}$ & 33 & 1989 & "Sportske novosti" & 35 \\
\hline 1989 & "Fußball magazin" & 28 & 1989 & "Glas Slavonije" & 25 \\
\hline \multirow[t]{2}{*}{1990} & "Zeit" & 12 & 1990 & "Tjednik odabranih priloga" & 20 \\
\hline & "Antisprichwörter" & 32 & & & \\
\hline 1982 & Band I & & & & \\
\hline 1985 & Band II & & & & \\
\hline \multirow[t]{2}{*}{1989} & Band III & & & & \\
\hline & & $\begin{array}{c}\text { insgesamt } \\
150\end{array}$ & & & $\begin{array}{c}\text { insgesamt } \\
140\end{array}$ \\
\hline
\end{tabular}


Tabelle 2: UMMODELLIERUNG DER SPRICHWORTSATZKOMPOSITION

\begin{tabular}{|c|c|c|c|}
\hline & DEUTSCH & KROATISCH & INSGESAMT \\
\hline Einfacher Satz wird redupliziert & ANTI 12 & 1 & 1 \\
\hline $\begin{array}{l}\text { Einfacher Satz wird zum } \\
\text { zusammengesetzten Satz }\end{array}$ & $\begin{array}{l}\text { SPIEGEL 21, } \\
\text { ANTI } 25\end{array}$ & $\begin{array}{l}\text { SD 41, SD 42, } \\
\text { SD 45, SN } 32\end{array}$ & 6 \\
\hline $\begin{array}{l}\text { Einfacher Satz wird auf eine } \\
\text { Wortgruppe reduziert }\end{array}$ & 1 & SD 58 & 1 \\
\hline $\begin{array}{l}\text { Zusammengesetzter Satz wird } \\
\text { redupliziert }\end{array}$ & ANTI 12 & I & 1 \\
\hline $\begin{array}{l}\text { Zusammengesetzter Satz wird zum } \\
\text { einfachen Satz }\end{array}$ & FUSSB 22 & SD 31, SD 37 & 3 \\
\hline $\begin{array}{l}\text { Zusammengesetzter Satz wird auf } \\
\text { eine Wortgruppe reduziert }\end{array}$ & FUSSB 27 & I & 1 \\
\hline $\begin{array}{l}\text { Präpositionierte Erweiterungen des } \\
\text { Satzes }\end{array}$ & FUSSB 10 & $\begin{array}{l}\text { SD } 27, \text { SD } 28, S D \\
38, S D 41, \text { SD } 45, \\
\text { SD } 57, \text { SN } 18\end{array}$ & 8 \\
\hline $\begin{array}{l}\text { Postpositionierte Erweiterungen des } \\
\text { Satzes }\end{array}$ & $\begin{array}{l}\text { WAZ 25, SPIEGEL } \\
16, \text { FUSSB } 10\end{array}$ & $\begin{array}{l}\text { SD 38, SD 57, } \\
\text { SN } 18\end{array}$ & 6 \\
\hline Interne Erweiterungen des Satzes & 1 & $\begin{array}{l}\text { SD 25, SD 27, } \\
\text { SD 28 }\end{array}$ & 3 \\
\hline Insgesamt & 10 & 20 & 30 \\
\hline
\end{tabular}

Tabelle 3: UMMODELLIERUNG DER SATZSTRUKTUR

\begin{tabular}{|c|c|c|c|}
\hline & DEUTSCH & KROATISCH & INSGESAMT \\
\hline $\begin{array}{l}\text { 2-Konstituenten-Satzstruktur: } 1 \\
\text { Konstituente wird eliminiert }\end{array}$ & $\begin{array}{l}\text { FUSSB 10, FUSSB } \\
18\end{array}$ & $\begin{array}{l}\text { SD } 3, \text { SD } 48, \text { SN } \\
12, \text { GS } 7\end{array}$ & 6 \\
\hline $\begin{array}{l}\text { 2-Konstituenten-Satzstruktur: } 1 \\
\text { Konstituente wird addiert }\end{array}$ & 1 & SD 45, SD 57 & 2 \\
\hline $\begin{array}{l}\text { 2-Konstituenten-Satzstruktur: } 3 \\
\text { Konstituenten werden addiert }\end{array}$ & I & SD 27, SD 28 & 2 \\
\hline $\begin{array}{l}\text { 3-Konstituenten-Satzstruktur: } 1 \\
\text { Konstituente wird eliminiert }\end{array}$ & $\begin{array}{l}\text { FUSSB 1, FUSSB } \\
25\end{array}$ & $\begin{array}{l}\text { SD 37, SD 54, SD } \\
55\end{array}$ & 5 \\
\hline $\begin{array}{l}\text { 3-Konstituenten-Satzstruktur: } 2 \\
\text { Konstituenten werden eliminiert }\end{array}$ & 1 & SN 1 , TOP 19 & 2 \\
\hline $\begin{array}{l}\text { 4-Konstituenten-Satzstruktur: } 3 \\
\text { Konstituenten werden eliminiert }\end{array}$ & I & SD 53 & 1 \\
\hline insgesamt & 4 & 14 & 18 \\
\hline
\end{tabular}


Tabelle 4: ÄNDERUNG DER SATZART

\begin{tabular}{|c|c|c|c|}
\hline & DEUTSCH & KROATISCH & INSGESAMT \\
\hline $\begin{array}{l}\text { Aussagesatz wird zum } \\
\text { Fragesatz }\end{array}$ & $\begin{array}{l}\text { SPIEGEL 7, } \\
\text { SPIEGEL } 21\end{array}$ & SD 8 & 3 \\
\hline $\begin{array}{l}\text { Imperativsatz wird zum } \\
\text { Aussagesatz }\end{array}$ & WAZ 29, WAZ 30 & SD 42 & 3 \\
\hline insgesamt & 4 & 2 & 6 \\
\hline
\end{tabular}

Tabelle 5: ÄNDERUNG DER WORTART INNERHALB VON KONSTITUENTEN

\begin{tabular}{|l|c|c|c|}
\hline & DEUTSCH & KROATISCH & INSGESAMT \\
\hline Verb wird zum Substantiv & SPIEGEL 16 & $/$ & 1 \\
Substantiv wird zum Verb & WAZ 25, FUSSB 18 & $/$ & 2 \\
Substantiv wird zum Adjektiv & $/$ & SN 1 & 1 \\
Substantiv wird zum Adverb & FUSSB 4 & $/$ & 1 \\
Substantiv wird zum Pronomen & $/$ & SN 30 & 1 \\
Adjektiv wird zum Substantiv & FUSSB 1 & SD 31 & 2 \\
Adverb wird zum Substantiv & FUSSB 22 & $/$ & 1 \\
\hline insgesamt & 6 & 3 & 9 \\
\hline
\end{tabular}

Tabelle 6: ÄNDERUNG DES WORTBILDUNGSMUSTERS DER KONSTITUENTEN

\begin{tabular}{|l|c|c|c|}
\hline & DEUTSCH & KROATISCH & INSGESAMT \\
\hline $\begin{array}{l}\text { Simplex wird zum } \\
\text { Kompositum }\end{array}$ & ANTI 31 & $/$ & 1 \\
\hline INSGESAMT & 1 & 0 & 1 \\
\hline
\end{tabular}


Tabele 7: ÄNDERUNG DER MORPHOLOGISCHEN KATEGORIEN INNERHALB VON VERBALEN KONSTITUENTEN

\begin{tabular}{|c|c|c|c|c|}
\hline & & DEUTSCH & KROATISCH & INSGESAMT \\
\hline \multirow[t]{2}{*}{ TEMPUS } & Präsens wird zum Futur & 1 & SD 57 & 1 \\
\hline & Präsens wird zum Perfekt & l & SD 24, SD 27, & 3 \\
\hline \multirow[t]{4}{*}{ MODUS } & Indikativ wird zum Konditional & 1 & SD 27 & 1 \\
\hline & Indikativ wird zum Imperativ & I & SN 11 & 1 \\
\hline & Imperativ wird zum Indikativ & 1 & SD 41, SD 41 & 2 \\
\hline & $\begin{array}{l}\text { Modalitätsgefärbtes Verbum } \\
\text { finitum wird zum Verbum } \\
\text { infinitivum im Indikativ }\end{array}$ & FUSSB 27 & 1 & 1 \\
\hline GENUS VERBI & Passiv wird zum Aktiv & I & SN 13 & 1 \\
\hline \multirow[t]{2}{*}{ PERSON } & 3. Person wird zur 1 . Person & I & SN 3 & 1 \\
\hline & 2. Person wird zur 3. Person & I & $\begin{array}{c}\text { WAZ } 29, \text { WAZ } \\
30\end{array}$ & I \\
\hline \multirow[t]{2}{*}{ NUMERUS } & Singular wird zum Plural / & SD 3 & 1 & \\
\hline & Plural wird zum Singular & $\begin{array}{c}\text { WAZ } 29, \text { WAZ } \\
30 \\
\end{array}$ & I & 2 \\
\hline \multicolumn{2}{|l|}{ insgesamt } & 5 & 11 & 16 \\
\hline
\end{tabular}

Tabelle 8: ÄNDERUNG DER MORPHOLOGISCHEN KATEGORIEN INNERHALB VON SUBSTANTIVISCHEN KONSTITUENTEN

\begin{tabular}{|c|c|c|c|c|}
\hline & & DEUTSCH & KROATISCH & INSGESAMT \\
\hline KASUS & $\begin{array}{l}\text { Substitution des Akkusativs } \\
\text { durch den Dativ }\end{array}$ & 1 & SD 54 & 1 \\
\hline insgesam & & 0 & 1 & 1 \\
\hline
\end{tabular}

Tabelle 9: SONSTIGE ÄNDERUNGEN

\begin{tabular}{|l|c|c|c|}
\hline & DEUTSCH & KROATISCH & INSGESAMT \\
\hline ÄNDERUNG DER REIHENFOLGE DER & & & \\
KONSTITUENTEN & & & \\
A+B+C-Reihenfolge wird zur B+A+C-Reihenfolge & $/$ & SD 12 & 1 \\
A+B+C-Reihenfolge wird zur A+C-Reihenfolge & $/$ & SD 54 & 1 \\
A+B-Reihenfolge wird zur B+A-Reihenfolge & FUSSB 10 & $/$ & 1 \\
\cline { 1 - 1 } SATZNEGATION & WAZ 31 & $/$ & 1 \\
WORTNEGATION & ANTI 31 & $/$ & 1 \\
\hline insgesamt & 3 & 2 & 5 \\
\hline
\end{tabular}

